\title{
Enhancing Design Education by Product Reverse Engineering
}

\author{
Kezheng Huang \\ Shandong University, Jinan, China (250061) \\ E-mail: huangkz@sdu.edu.cn
}

\begin{abstract}
As science and technology develops faster and faster, the accumulation of knowledge is exponential over time. Engineering education must keep up with the changing environment including engineering practice. As each individual's capability is limited, engineering students need choosing right stuff to learn so that they can graduate as qualified engineers with both broad knowledge and practical skills as required in industry. In this paper, the current engineering education is discussed with some trends, such as creativity training as most have insisted in project-based hands-on design education, broad knowledge including essential engineering science knowledge. As a comprehensive discipline, design engineering courses exist to teach engineering design fundamental. Due to immature design theory and methodology, the "learning by doing" approach is widely accepted to complement current engineering design education. In this paper, an integrated effort is introduced which combines together the two basic aspects, knowledge and skill, in order to increase the half-life of engineering knowledge and enhance the hands-on skills at the same time. Based on new development in design research, an experimental design education using Product Reverse Engineering (PRE) as education tool, is introduced with initial evaluation for suitability in design education.
\end{abstract}

\section{Introduction}

We live in a world where the accumulation of knowledge is exponential over time, and where the ability to continuously learn and make sound judgments is essential to survival [1]. Also as a result of global economy, the practice of engineering is changing and the pace of this change is accelerating. The new environment is challenging both to engineering students and engineering educators. It is especially so if the B.S. for engineering graduates is still treated as a professional degree [2].

The engineering education has swung from the extreme practicality of the apprenticeship programs prevalent early of last century to the extreme theory taught in later decades to engineers who were encouraged to be "applied scientists" [3]. The last major curriculum change in engineering, the move to "engineering science," occurred following WWII [2]. In the 1950s, the "specialty" education was introduced into the Chinese higher educational system [4]. The specialty education is based on the belief that knowledge can be transmitted via indirect experiences. Widely discussed shortcomings of the current specialty education include narrowly defined scope of specialty and less emphasis on the student's ability to creatively apply theories in practices. A common practice of broadening the curricula is to add new courses to existing curricula. As a result the students become over burdened by a larger number of courses [5].

According to analysis of inventive design intelligence, a good grasp of broad knowledge including most updated information, and creative utilization in design thinking and practice is fundamental to real inventions [6]. In 
search of new paradigms for better education, an integrated effort is made to combine the two basic aspects of engineering education, knowledge learning and capability training, in order to increase the half-life of engineering knowledge and enhance the hands-on skills in practice. Learning generic engineering knowledge during hands-on experience is the essence of our approach. In this paper, based on new development in our design research, an experimental design education using Product Reverse Engineering (PRE) [7] concept as a new education tool is introduced with initial evaluation for suitability in design education.

The remaining of the paper is organized as follows: Section 2 discusses related researches on design education; The PRE is introduced briefly in section 3; Emphasis will be on section 4 where the implementation of the experimental design education course is introduced in detail with specific projects examples; and finally comes the conclusions drawn from the experience of this education effort discussed in the paper.

\section{Related Researches}

Historically, universities have taken the responsibility for rigorous theoretical and technical training in subjects that include the basic sciences and fundamentals of engineering, while industry has been responsible for making engineering graduates contributors to specific tasks important to the company and its core competency. In this division of training, however, no one teaches students how to apply fundamental engineering principles to practical problems. To make matters worse, faculty often ignore engineering relevance of basic theory and the students then reject these fundamentals; in both cases engineering performance suffers [8]. The objective of education is for industrial practice. The closer the education environment is to the practice, the easier the students will adapt to work environment. However, the difference between education and industry is inevitable. To bridge this kind of gap between theory and practice, a variety of efforts have been made by many engineering educators. These efforts can be classified into two basic categories:

(1) Theoretical improvement and development:

Better fundamental theory that solves wide range of industrial problems is always the ultimate goal of academic efforts; that is why many have insisted that the undergraduate curriculum should teach (only) the fundamentals though the difficulty comes when we try to decide which fundamentals are truly fundamental [2]. Introduction of new synthesis disciplines that cut across multi-subjects is also useful. E.g. Dr. W. A. Wulf, President of National Academy of Engineering, USA, has his own definition of engineering as "design under constraint" [2]. It is also believed that design is the essence of engineering and the design-directed approach has been adopted in implementing the CDIO initiative [9-10].

(2) Development of engineering education approaches closer to industrial practice:

Work experience internship and Engineering design in industry [8] is most direct training approach similar to apprenticeship education. Experimental environment like LEGO is easy and more cost-effective to implement [11]. However, its environment is different from industry practice. Due to the nature of engineering, especially design engineering, theory does not solve all the problems in industrial practice. Therefore, currently, particularly in design education, educators seem to be questioning whether the lack of hands-on experience may be harming their students' educational experience. Many schools are striving to include more concrete experience in both their theoretical and design courses [3]. One technique that is popular with educators is incorporating "hands-on" projects into engineering courses and a new effective approach is to use mechanical dissection [12][13][14]. The underlying philosophy is explained by Sheppard of Stanford University [15]. Dissection has been utilized for further design education purposes, such as teaching seniors Design for Dissassembly 
and Design for Recyclability techniques [16].

In the former, one approach that has proved successful is teaching students a structured, problem-solving method that they may use to tackle open-ended design problems. Of these methodologies, four of the most popular are those of Otto and Wood [17], Pahl and Beitz [18], Ullman [19], and Ulrich/Eppinger [20].

As the latter approaches develop, a question has been raised that whether the inclusion of hands-on projects will fully solve the problem. "Arguably, the selfdiscovery obtained in surmounting a large design problem has its educational benefit. However, the enormous expenditure of time often frustrates the student." [21]

Further, some of the common deficiencies in the design curricula have been summarized, such as the difficulty of solving extremely open-ended problems as engineered systems are becoming larger and more complex involving components and processes from many more fields of engineering, and design modeling, analysis, and experimentation. And so dissection projects should be used to teach design and be coupled with structured methodologies [3].

Another big issue is that in many cases there is no theory that can be applied to practical open-ended problems, such as conceptual design of mechanical products, and that is exactly the true reason why the latter has been paid so much attention. In these cases, even if you have some experience in one product, you could not be able to tackle a new design task. Therefore, development of design theory and incorporation into design education courses is one of the urgent and vital approaches to making essential progress in design education. And a dynamic balance between concrete and theoretical experience should be kept for the best possible performance of the students. Along this way, extracting, condensing, refining, and systemizing related knowledge is important instead of placing students in explosive information.

Structural (embodiment) design plays a critical role in product design process, which transforms the abstract principle into a group of specific components.
However, due to the extreme variety of products and components structure, the uniformity and consistency in structure expression and structure design is a huge challenge. Hence, the existing design theory does not satisfy effectively the human desire to accumulate and reuse the knowledge and experience of product design. Development of the product structure design automation theory [22] is a new and promising step for design theory. Growth design modeling established a new and operable product structure design process [23]. Based on the above theoretical development, Product Reverse Engineering has been proposed [7]. In this paper, PRE will be applied to design education and experience of using PRE at SDU is introduced.

\section{PRE and New Course Structure}

In this section, PRE will be introduced briefly so that better understanding can be obtained

\subsection{Product Structure Design Process and PRE}

There is a large amount of knowledge and technology about product forward design based on human engineering practice and experience. However, the creative (conceptual) process of human thinking is unclear. The product design process, particular the process of innovation, is mostly mysterious. The immature design theory and dependability on human design experience determines the poor operability and unknown reversibility of product design, and the lack of effective (innovative) engineering design method and support tools.

Structural (embodiment) design plays a critical role in product design process, which transforms the abstract principle into a group of specific components. However, due to the extreme variety of products and components structure, the uniformity and consistency in structure expression and structure design is a huge challenge. Currently, it is impossible to describe the design process of a specific products structure. Hence, the existing design theory does not satisfy effectively 
the human desire to accumulate and reuse the knowledge and experience of product design. Growth design modeling established a new and operable product structure design process.

Theoretically, Product Reverse Engineering is defined in this paper as a creative engineering, which reconstitutes new product genes based on existing products and related information under the guidance of Product Genetic Engineering concept. The essence of PRE is to reconstitute a feasible design process so as to make as good as possible use of the design ideas and key technologies implied in existing products. Technically, taking the physical models, drawings, and 3D CAD models as resource and Growth Design methodology as the guide, PRE will help designer to master the design ideas and key technologies and extract Product Genes based on product functional analysis and designer's knowledge and experience. Therefore, it can meet the functional requirements for innovation design of a product family by referring to existing products, such as product size, tolerance, materials, etc.

\subsection{PRE Framework}

The overall framework for PRE, as shown in figure 1, is composed of three layers: engineering theory, technology tools and application systems. The theory layer is responsible for solving basic issues as operability and reversibility of product design process. Growth design process is the key concepts involved.

The technology layer includes key methods and tools for reconstitution of product design process. PRE software systems are the main form of this layer that includes various software modules and functional tools. Product gene base building will help speed up innovation in design practice.

The application layer contains specific application systems with functions required for practical PRE work, where specific products can be analyzed and their genes extracted; and specific product processes can be formed for designers to use further. An application flow chart is given in Fig. 2.

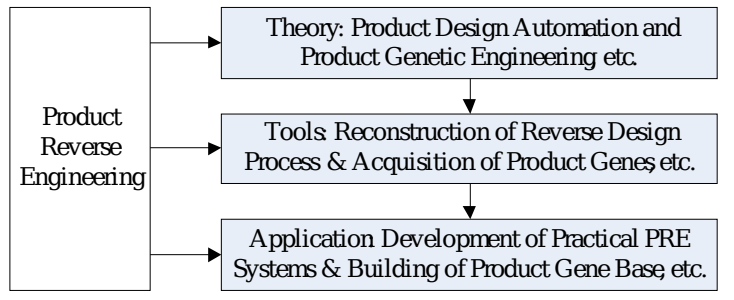

Figure 1 Overall Framework for PRE

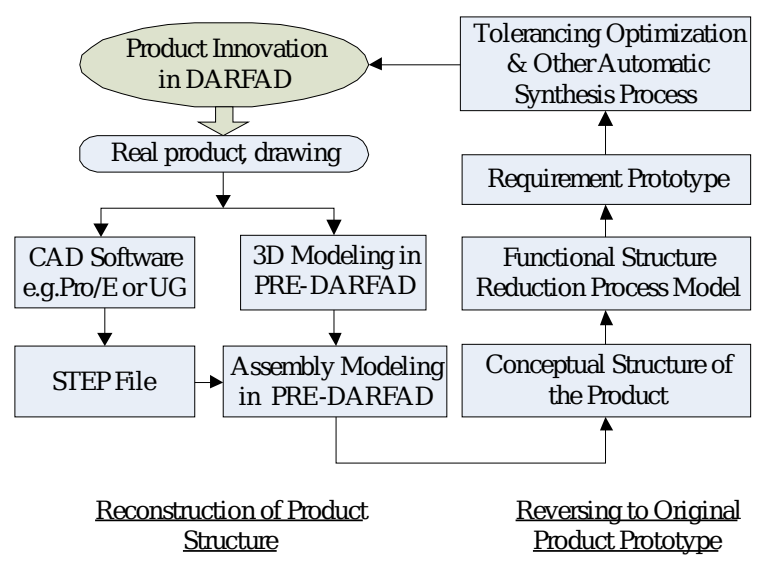

Figure 2 Flow chart of PRE-DARFAD system

\subsection{Course Structure}

The background information for engineering design is as follows: Current curriculum includes (1) First year: Mechanical drafting; Computer Aided Drafting and Graphics; The Innovation Skills Training course is provided by University Engineering Training Center for freshman. (2) Second year: Engineering mechanics, Metalworking and practice; electrotechnics, Mechanical design principle (Mechanism), practice and design projects; (3) Third year: Machine design, innovative machine design and design projects; Design methodology; Experimental innovation design synthesis; (4) Fourth year: Management and Production practice, Graduation design projects. This course has been designated for senior students and graduate students to better learn design methodology and product design technology.

\section{Lecture sessions:}

(1) Introduction and product's objectives 
In this session, instructor needs to explain the differences of the approach used in this course from traditional design methodologies courses. Several existing products, new/used, simple in structure and light in weight should be brought to classroom.

Discussion on products' requirements and functions will place an emphasis on visual representation of product concepts leading to "prototypes".

(2) Functional surfaces on products and components:

Functional surface is a fundamental concept for the new course which serves as a information carrier bridging function and structure at different levels.

(3) Representation of conceptual components

All components will be reorganized in certain order and their representation will be different from traditional one, see Fig.3 for an example.
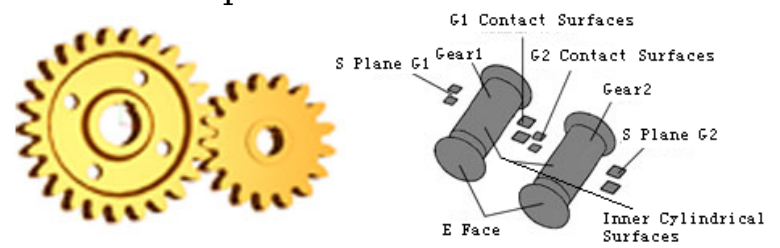

Figure 3 Conceptual representation of a gear pair based on functional surfaces

(4) Conceptual structure of product A product's conceptual structure consists of functional surfaces of all the components belonging to it. Components are connected through GeneratingLocation-Surfaces (GLS) and MakingLocation-Surfaces (MLS), as shown in Fig.4 in sequence. All the functional surfaces in assembly position form a conceptual structure for a product (see Fig.5).

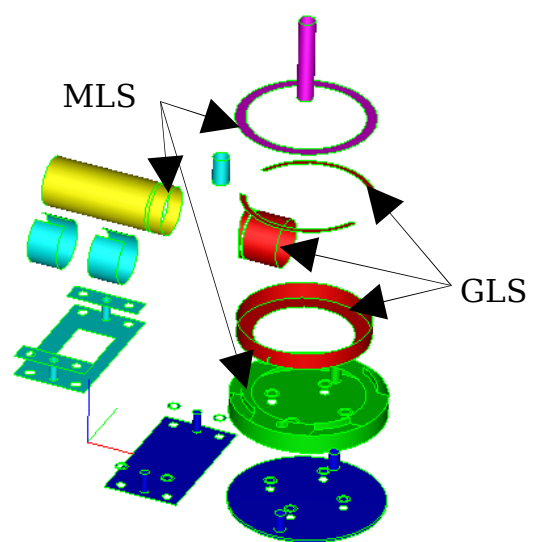

Figure 4 Conceptual structure of a fixture for machining piston and its Functional surfaces

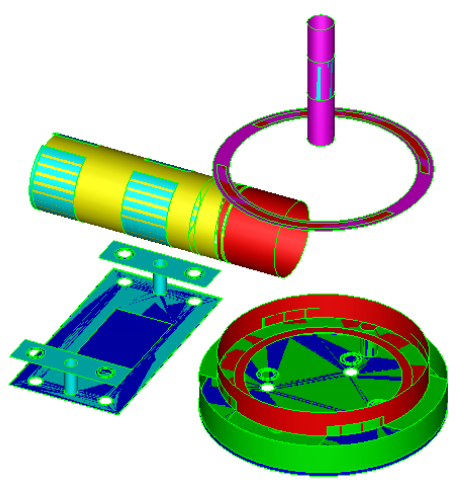

Figure 5 Conceptual structure of the Fixture

(5) Forward design and reverse design process

Introduction of theoretical fundamentals of PRE is made, operable product structure design process is discussed based on structural design automation theory; Reverse mechanism for structure design process based on product conceptual structure and corresponding software Pre/ $\mathrm{D}$ is introduced and demonstrated in detail;

(6) Analysis at conceptual level

Tolerancing at conceptual level will be discussed and software module in Pre/D will be introduced, see Fig. 6 for a snapshot from the demonstration. 


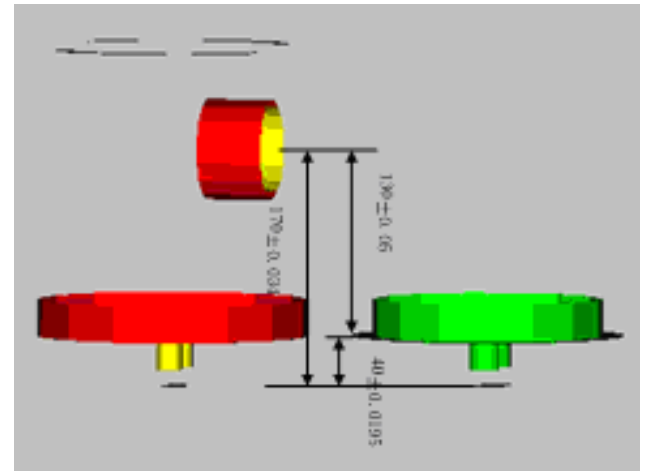

Figure 6 Tolerance display during conceptual design

\section{Lab sessions:}

(1) Selection of appropriate products:

When considering existing products for course projects, the main factors include cost (less than 200YMB) and complexity of product structure (less than 50 components). For new products, usually small and portable ones are chosen; for old and used, larger and heavier ones selected. Expensive ones usually come from partnering companies, such as Solar Water Heater from Linuo Group, or sponsored by research grants, like CNSF. For used product, care need be taken for its ease to disassembly.

(2) Analysis and recording of existing products

For easy re-assembly, pre-disassembly work includes analysis and recording of the whole product structure;

(3) Dissection

When dissecting, usually keep components complete and undamaged; and record relations among different components by rough sketching or taking photos. Time for disassembly will be taken for each component for later disassemblibility analysis. A Bill of Material also will be set up when dissection is done.

(4) 3D Modeling and Assembly by Pro/Engineer or other CAD Packages available

After dissection, components are usually assigned to each member of a group for further modeling. Then, component models will be put together to form an assembly model. As shown in Fig. 7 is the assembly model for the piston machining fixture.

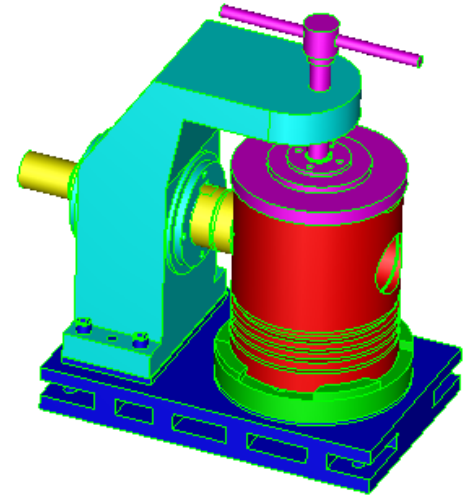

Figure 7 3D assembly model of the Fixture

(5) Using Pre/D to reverse design process Pre/D is a software prototype for Product Reverse Engineering developed at Key CAD Lab. Shandong University with all main functions included, such as 3D Fast Modeling, Simple Assembly, Importing 3D Assembly Model from STEP and other format, Extraction of Product Conceptual Structure, Reverse Engineering Product Design Process, Knowledge Reorganizing, Conceptual Analysis like Tolerancing, Product Knowledge Base Building, etc.

The snapshots of 3 steps of a reverse design process for the piston fixture produced by operating Pre/D is shown in Fig. 8 which will be explained later.

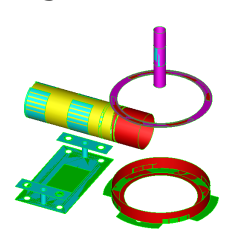

(1)

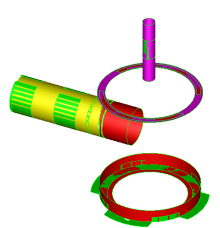

(2)

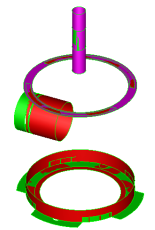

(3)
Figure 8 Reverse design process.

In Fig. 9, the final result of the reverse design process is shown, that is, the "original prototype" of the fixture which visually represents the original requirements "generalized location" for the fixture.

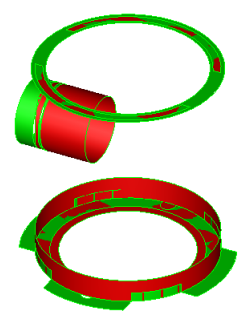


Figure 9 Original requirements prototype obtained through revere process

(6) Knowledge searching and extraction Assignments are given to students that require searching related useful knowledge about the product he/she is working on. Resources include library, internet, and patent documents. According to specific reverse steps, extraction of useful and reasonable knowledge from a vast of knowledge obtained in searching should be performed.
(7) Product
knowledge
reverse engineering

After the reverse design process is finished, a forward design process is easily established:

Fig. 9〕 Fig. 8 (3) $\square \quad$ Fig. 8 (2) $\square \quad$ Fig. 8 (1)

\section{(1) Fig. 7}

Based on the forward design process, associate corresponding knowledge to each design step so that the knowledge about the product design is integrated into the specific design process. Put all product design processes together, a new type of product knowledge base will be available for future reuse.

(8) Product redesign based on PRE

Based on the design process acquired above, the following re-design process can be made to improve the product parametrically or adaptively:

Start the design process with a well-expressed requirements prototype in visual form which consists of some functional surfaces. For this fixture design, it represents a conceptual "generalized location" plan;

Decompose the top locating (functional) surface and make it another component "Top Clamp", then mount it back on the prototype by screw connection; It is operated manually by means of lever;

(1) Take apart the Locating surface for the pinhole to form a new part "Locating Pin", then put it back and allow it slide into its locating position; It is easy to manufacture and heat-treated for resistance to wear.

( Separate the supporting surfaces for Top Clamp and Locating Pin from the prototype and transform into a new part "Column", then connect it with the Bottom Support;

( To guarantee the accuracy and wear resistance for the bottom locating surfaces, isolate them into a new component "Locating Base" and reconnect it to the Bottom Support mechanically for easy exchangeability.

(9) Using Pre/D for Tolerancing at Conceptual Level

(10)Proposing product improvement solutions

\section{Implementation of Design Project}

\subsection{Project Description}

Selecting an exiting used mechanical product, appliances or industrial, that you are interested in and is available economically and technically feasible to accomplish in one semester. Form a team of 2-5 according to the complexity of the product chosen.

\subsection{Requirements}

Once a product has been chosen, each team is required to perform the lab sessions listed in last section based on lecture sessions.

\subsection{Lab Exercises}

(1) Selection of appropriate products: Selection of products has been various, such as a used Table Drill Press at cost of $120 \mathrm{YMB}$ and used Washing Machine at cost of 180YMB from used tools/ appliances markets, and Solar Water Heater from partner company.

(2) Analysis and recording of existing products

(3) Dissection

In Fig. 10, a sample product --- washing machine is shown exploded after dissection. In the dissection, disassembly of mechanical structure is easy, but some difficulties have been encountered with electrical parts tangled together. 


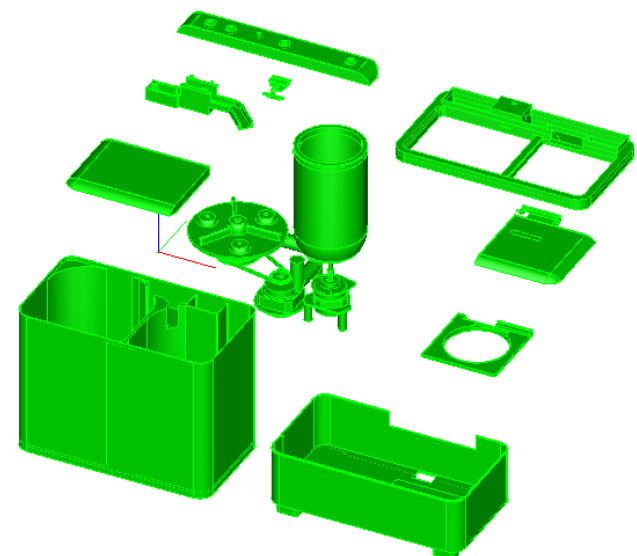

Figure 10 A washing machine after dissection

(4) 3D Modeling and Assembly by Pro/Engineer

After dissection of a product, 3D component modeling and whole product assembly modeling will take up quite some time and need team work to prevent long dull and boring experience. The drill press model is shown in Fig. 11.

Basic analysis work is also required for later use. Part relationship analysis based on functional surface is important task for students to better understand mechanical structure. A new approach of expressing this kind of relationship has been proposed by the students themselves --- they call it "Block Diagram for Function Surface Relationship". An example is shown in Fig. 12.

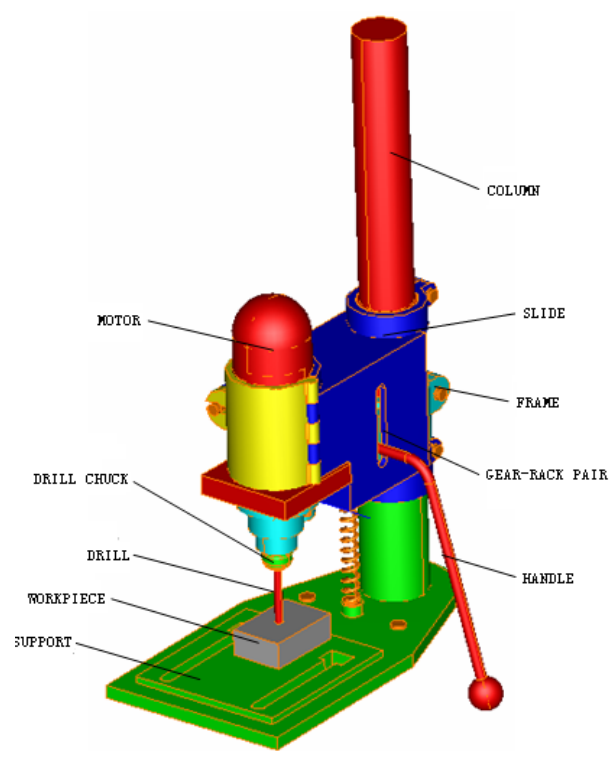

Figure 11 A 3D assembly model of a table drill press

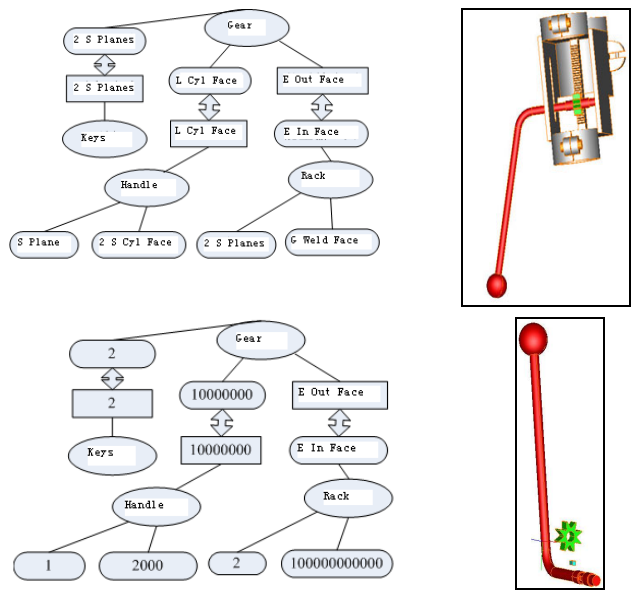

Figure 12 Relation model for 2 functional components

The block diagram is also established for the whole product structure. Fig. 13 shows one for the drill press.

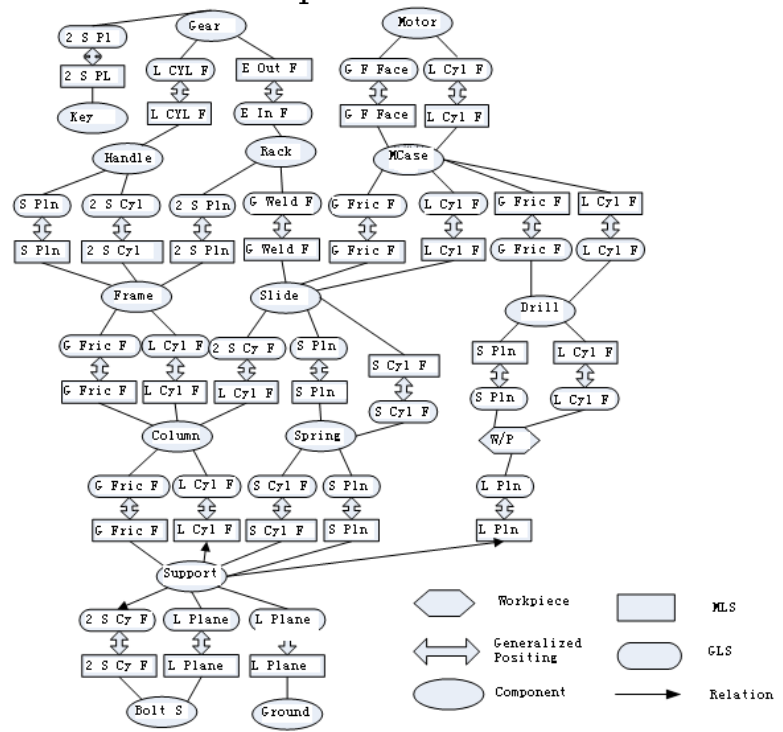

Figure 13 Product relationship model

(5) Knowledge searching and extraction

(6) Using Pre/D to reverse design process

In Pre/D, reverse process is made with result as shown in Fig.14 for the drill press. 


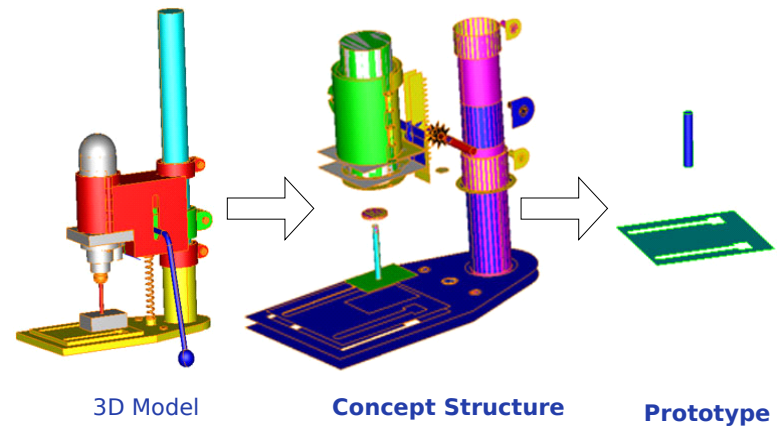

Figure 14 Drill press reverse process (7) Product knowledge reverse engineering

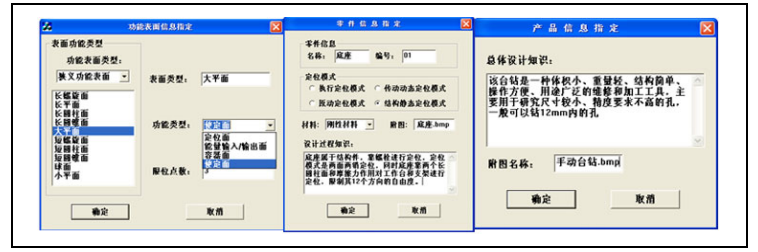

Figure 15 A snapshot of knowledge association

Students are required to associate all available design knowledge to corresponding design steps. And finally print out a detailed design report, which justify the forward design procedure with appropriate design principles and knowledge. A snapshot of knowledge association is shown in Fig.15.

(8) Proposing product improvement solutions

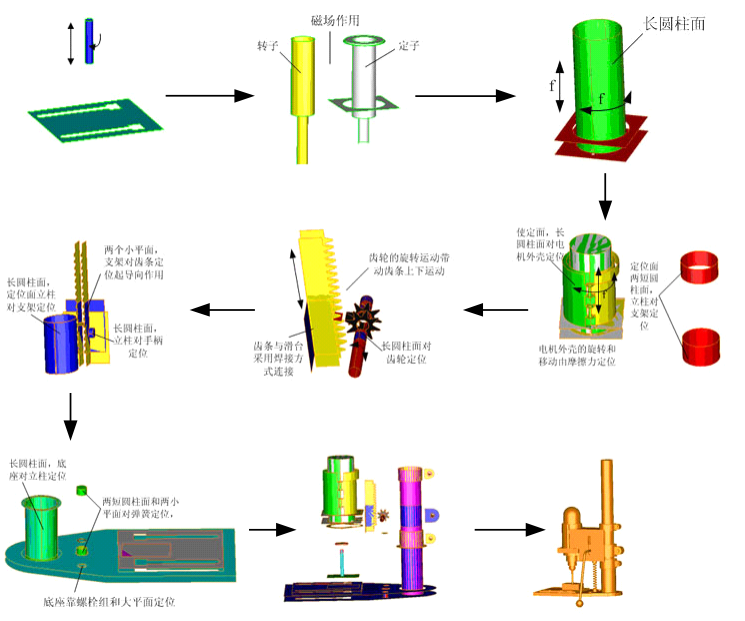

Figure 16 Forward design process for improvement
The forward design process is established for the drill press and shown in Fig.16. Improvements can be proposed at each design step by applying better knowledge and changing the product structure growth direction.

(9) Using Pre/D for Tolerancing

\subsection{Initial Evaluation}

This experimental design education projects have been examined by other faculty and compared with other course projects with following results.

(1) Appropriate exposure to real product, much more controllable than completely open-ended projects;

(2) Both hands on experience and abilities to analyze other mechanical product structures are acquired;

(3) Comprehensive training in both design and CAD software, involving different CAD packages and file formats;

(4) Obtaining some feel about design for disassembly when dissecting old and rusted machines;

(5) Better understanding the importance of the goals for product design based on good grasp of product prototype analysis and visual modeling;

(6) Acquiring better conception by experiencing specific and step-by-step procedures for conceptual design of mechanical products.

\section{Conclusions}

Through the PRE based design education practice, the following conclusions can be drawn:

(1) Product oriented Reverse Engineering (PRE) can not only keep the advantages of hands-on experience, but also enhance students' abilities in product structure understanding and improving.

(2) Introduction of product structure design automation theory together with effective software tools is promising in enabling students to have generalpurpose analysis capability for all kinds of product structures based on the short period of hands-on experience. 
(3) The idea of developing generic knowledge and knowledge organization around existing product can be an effective way for engineering knowledge reuse.

Some obvious shortcomings also exist in the PRE based education activity. The most difficult one is that students used to traditional way of thinking take longer time than expected to adapt to this new system. Then comes the problem of applying generalized location principle to some structures where the overall objectives of the product seem having no clear connection. However, this experimental design education activity is inspiring and promising if further effort is made in future.

\section{Acknowledgement}

Many senior students and graduate students participated in the experimental design education activities discussed about in this paper. The author would like to thank all them for their participance, especially to W. G. Wang, Q. B. Meng, B. Li, S. F. Lu, J. J. Wang, S. Y. Lin, J. X. Jia, and W. B. Wang for their excellent work.

\section{References}

[1] T. R. Kuphaldt, "Socratic Electronics", http:// openbookproject.net/books/Socratic / index.html, 2008

[2] W. A. Wulf, "The Urgency of Engineering Education Reform", The Bridge, The National Academy of Engineering, Spring 1998, V.28 No.1

[3] K. L. Wood, D. Jensen, J. Bezdek, K. N. Otto, "Reverse engineering and redesign: Courses to incrementally and systematically teach design", Journal of Engineering Education, Jul 2001.

[4] Jianhua $\mathrm{Hu}$, "The Origin of Modern Chinese Higher Educational System: the Higher Educational Reform in the 1950s", Nanjing Teachers University Press, 2001 (In Chinese)

[5] P. Gu, M. F. Shen, X. H. Lu, "Curricular Reform Based on the CDIO Initiative in Shantou University", Proc. of the 3rd International CDIO Conference, MIT, Cambridge, Massachusetts, June 11-14, 2007
[6] K. Z. Huang, "Study on Intelligent Design of Complex Surface Machining Systems", PhD Dissertation, Shandong University, Jinan, 1993

[7] K. Z. Huang, "Product Reverse Engineering based on Growth Design Process", Proc. of ASME DETC2007/ $D A C$-35827, Las Vegas, USA

[8] D. Dunn-Rankin, J. E. Bobrow, K. D.Mease, J. M. McCarthy, "Engineering design in industry: Teaching students and faculty to apply engineering science in design", Journal of Engineering Education, Jul 1998

[9] Ian Yellowley and Peihua Gu, "Design Directed Engineering Education", Journal of Engineering Design and Innovation, Issue 1, 2005.

[10] P. Gu, X. H. Lu, G. J. Xiong, S. P. Li, M. F. Shen, "Development of design directed engineering curriculum based on CDIO Framework", World Transaction on Engineering and Technology Education, Vol 5. No. 2, 2006, pp267-270

[11] Puett, J.F., III, "LEGOTM and the Art of Design Education," ASEE Annual Conference Proceedings, vol. 2, 1995, pp. 27 72-2778

[12] Agogino, A.M., et al., "Making Connections to Engineering During the First Two Years," Frontiers in Education toward 2000, IEEE, 1992, pp.563-569.

[13] Carlson, L.E., et al., "First Year Engineering Projects: An Interdisciplinary, Hands-on Introduction to Engineering," ASEE Annual Conference Proceedings, vol. 2, 1995, pp. 2039-2043.

[14] Niku, S.B., "Metamorphic Mechanical Dissection and Design in Freshman Engineering Courses," ASEE Annual Conference Proceedings, vol. 2, 1995, pp.2035 -2038

[15] Sheppard, S., "Mechanical Dissection: An Experience in How Things Work," Engineering Foundation Conference on Engineering Education: Curriculum Innovation \& Integration, January, 1992, Santa Barbara, CA pp. 5-10

[16] Garrett, R.W., "Design for Disassembly of Household Appliances in a Senior Design Project," ASEE Annual Conference Proceedings, vol. 2, 1993, pp.2060-2067 
[17] Marin, J.A., Armstrong, J.E. and J.L. Kays, "Elements of an Optimal Capstone Design Experience," Journal of Engineering Education, vol. 88, no. 1, Jan., 1999, p. 19

[18] G. Pahl, G., W. Beitz, Engineering Design, Springer-Verlag, New York, 1988

[19] D.G. Ullman, The Mechanical Design Process, McGraw-Hill, New York, 1992

[20] K. Ulrich, S. Eppinger, Product Design and Development, McGraw-Hill, NY, 1995

[21] Toomey, Capt. CJ., and Lt. Col. T.A. Lenox, "Introducing the Undergraduate Engineer to the Design Process," ASEE Annual Conference Proceedings, vol. 1, 1991, pp. 370-374

[22] Huang KZ (2006) "Generalized Positioning Principle and Structural Design Automation Theory", http://www.paper.edu.cn/downloadpaper.p hp?serial number $=200602-84$. Accessed 30 Feb 2006(in Chinese)

[23] K. Z. Huang, "Growth design modeling", Proceedings of DETC\&CIE: 32nd Design Automation Conference, Philadelphia, Sept. 10-13, 2006 